\title{
Microsurgical vasovasostomy: An option for men with post vasectomy psychological distress
}

\author{
Saad Elzanaty* \\ Department of Translational Medicine, Skåne University Hospital, Lund University, Malmö, Sweden
}

Received: October 5, 2021

Accepted: November 8, 2021

Online Published: November 17, 2021

DOI: $10.5430 /$ dcc.v8n4p5

URL: https://doi.org/10.5430/dcc.v8n4p5

\begin{abstract}
Vasectomy is a practical and straightforward approach to birth control. This paper presented a 31-year-old patient who desired to restore his fertility five years after being vasectomized. He met several obstacles. He developed severe psychological distress with symptoms of stress, anxiety, and aggression. He underwent microsurgical vasovasostomy, and vassal patency was confirmed by return of spermatozoa in semen samples 6 and 10 weeks after surgery, and symptoms of psychological distress disappeared. Preoperative vasectomy counseling should include information about vasectomy reversal. At the most, vasectomy reversal can be considered in selected men with psychological problems due to vasectomy. Microsurgical training should be offered to more urological surgeons, especially those who are interested in andrology.
\end{abstract}

Key Words: Infertility, Psychological distress, Vasectomy, Microsurgical vasovasostomy

\section{INTRODUCTION}

Vasectomy is an effective tool of birth control worldwide, ${ }^{[1]}$ with approximately 500,000 men in the United States ${ }^{[2]}$ and 30,000 men in Europe ${ }^{[3]}$ undergoing vasectomy yearly.

However, up to $6 \%$ of vasectomized men requested vasectomy reversal due to changes in the life cycle, such as separation and remarriage, the death of a child, a wish for further children within the same relationship, and altered financial circumstances. $^{[4,5]}$

Known complications of the procedure include hematoma formation, infection, vasectomy failure, short-term scrotal pain, sperm granuloma, the development of antispam antibodies, and long-term chronic scrotal pain syndrome. This paper presents a case of a man who developed severe psychological distress since he desired to restore his fertility following vasectomy but met several obstacles.

\section{Case Presentation}

A 31-year-old man underwent vasectomy five years ago. Three years later, the couple experienced divorce, and he desired to restore his fertility. He met several obstacles, including no institute performing vasectomy reversal in his region, and the Swedish national health care system does not cover the procedure. In consequence, he expressed serious psychological distress with symptoms of stress, defined as a normal reaction to everybody pressure which can become unhealthy when it upsets man's day-to-day functioning; anxiety, defined as an emotion characterized by feelings of tension, worried thoughts, and physical changes like increased blood pressure; and aggression, defined as an emotion characterizing by antagonism toward someone or something in an attempt to express negative feelings (American Psychological Association). The patient denied such symptoms before vasectomy. He was offered a referral to a mental health

\footnotetext{
*Correspondence: Saad Elzanaty; Email: saad.elzanaty@med.lu.se; Address: Department of Translational Medicine, Skåne University Hospital, Lund University, Jan Waldenströms gata 35, 21428 Malmö, Sweden. 
professional, but he refused. Therefore, a diagnosis of psychological disease was not made by a professional in this field. He was scheduled for microsurgical vasovasostomy at the Department of urology, Ystad Hospital, Ystad, Sweden.

The testicular size was measured using an orchidometer, the right testis was $12 \mathrm{ml}$, and the left testis was $15 \mathrm{ml}$. Both were of normal consistency. The epididymal head was dilated on both sides, otherwise standard. Examination of the vas deferens revealed a 1-2 cm vassal defect after the previous vasectomy, approximately $3-\mathrm{cm}$ from the upper testicular pole. The patient did not undergo any other uro-genital operations and was not taken any medications.

\section{Surgical approach}

Under general anesthesia, the testis was delivered through a bilateral 3-4 cm vertical scrotal incision. The site where vasectomy was performed was easy to identify. The ends of the vas deferens were carefully mobilized in order to ensure a tension-free anastomosis. Therefore, the scar tissues were excised, and both ends were then dilated carefully with fine lacrimal probes. Next, slight pressure was applied on the testis, and the secretion from the testicular part of the vas deferens was examined with a light microscope for the presence of spermatozoa. The secretions from both sides were clear, copious, and microscopic examination revealed sufficient motile spermatozoa from the left side and a few non-motile spermatozoa from the right side.

The vas deferens were viewed by magnifying $\times 3$ to $\times 16$ using a microscope (OMPI ORL S5; Carl Zeiss) with hand controls of focussing and zooming and a one-head unite. A 9-0 Nylon suture material was used to create the one-layer anastomosis. All sutures were interrupted, approximating both ends of the vas deferens, with five sutures in the front and three sutures at the back. A few perivasal approximating sutures with 6-0 Proline were added to reduce an anastomosis tension. The patient was observed in the postoperative Department and was discharged on the same day. No postoperative complications (hematoma or infection) were reported. Semen analysis was performed 6- and 10-weeks postoperative. The patient was assessed for his psychological status 3 and 6 months later. The assessment was done by interviewing the patient, where he expressed his word reflections on his mental health before and after surgery.

\section{RESUlts}

The operation time was 122 minutes. Spermatozoa were found in the ejaculate 6 and 10 weeks after surgery (see Table 1). The symptoms of psychological distress disappeared entirely, and the patient returned to his normal psychological behavior as he described himself during the postoperative interviews.

Table 1. Semen parameters 6 and 10 weeks after microsurgical vasovasostomy for vasectomy reversal in a 31-year-old man who underwent vasectomy 5 years ago

\begin{tabular}{lll}
\hline \multirow{2}{*}{ Variables } & \multicolumn{2}{c}{ Duration since operation } \\
\cline { 2 - 3 } & 6-weeks & 10-weeks \\
\hline Abstinence time (days) & 1.0 & 5.0 \\
Semen volume (ml) & 2.6 & 5.8 \\
Sperm concentration $\left(\times 10^{6} \mathrm{ml}\right)$ & 2.1 & 4.7 \\
Total sperm count $\left(\times 10^{6}\right.$ ejaculate) & 5.6 & 27 \\
Progressive motile spermatozoa (\%) & 25 & 45 \\
Non-progressive motile spermatozoa (\%) & 40 & 25 \\
Total motile spermatozoa (\%) & 65 & 70 \\
Immotile spermatozoa (\%) & 35 & 30 \\
\hline
\end{tabular}

\section{Discussion}

According to the European association of urology guidelines on vasectomy, counseling about vasectomy must address the irreversible procedure. ${ }^{[6]}$ According to the American urologic association guidelines on vasectomy, the minimum and necessary concepts that should be discussed in a preoperative vasectomy consultation include information about the possibility of vasectomy reversal and sperm retrieval with in vitro fertilization. ${ }^{[7]}$

Indeed, vasectomy is not irreversible since up to $6 \%$ of vasectomized men requested vasectomy reversal for different reasons. The presented man did meet several obstacles to restoring his fertility. In consequence, he developed severe psychological distress that affected him on the personal and professional levels. After successful microsurgical vasovasostomy with the return of spermatozoa in the ejaculate, the distress disappeared, and he is doing well. Zhao et al. found that the mean score of the Beck Depression Inventory was higher in men with vasectomy compared to those without vasectomy. The authors suggested that men with vasectomy may benefit from professional psychological counseling. ${ }^{[8]}$ Unfortunately, the psychological distress of the present man did not assess using a professional tool.

Microsurgical vasovasostomy is considered the method of choice for vasectomy reversal. ${ }^{[9]}$ The decision to perform vasovasostomy depends on the macroscopic and microscopic characteristics of the intra-operative vassal secretion. If the vassal secretion contains spermatozoa, then vasovasostomy should be performed. If no spermatozoa and the vassal secretion is clear and copious, most surgeons would still perform vasovasostomy. ${ }^{[10]}$ The intra-operative vassal secretion from the present patient contains spermatozoa; therefore, the decision was to perform vasovasostomy. 
The method of vasal anastomosis used herein was the onelayer approach. Compared to the two-layer system, the onelayer vasovasostomy is easier and quicker to perform and has fewer sutures pass through the lumen, which theoretically lowers the risk of suture granuloma and subsequent stricture. A theoretical disadvantage of the one-layer vasovasostomy is that the mucosal approximation may not be as reliable as in the two-layer vasovasostomy.

Herein, the patency of the vas was confirmed by the presence of spermatozoa in the seminal fluid 6- and 10-weeks postoperative with the improvement of sperm characteristics over time. This improvement can be attributed to the more prolonged time of abstinence reported with the second semen sample. The length of sexual abstinence has been reported to associate sperm characteristics. ${ }^{[11]}$ It may also be related to the length of time since surgery. In addition, it has been documented that sperm quality improves over time following vasovasostomy. ${ }^{[12]}$

\section{Conclusion}

The preoperative vasectomy counseling should include information about vasectomy reversal. At the most, vasectomy reversal can be considered in selected men with psychological problems due to vasectomy. Microsurgical training should be offered to urological surgeons, especially those who are working with andrology.

\section{CONFlicts of InTEREST Disclosure}

The author declares no conflicts of interest.

\section{REFERENCES}

[1] Pile JM, Barone MA. Demographics of vasectomy-USA and international. Urol Clin North Am. 2009; 36: 295-305. PMid:19643232. https://doi.org/10.1016/j.ucl.2009.05.006

[2] Eisenberg ML, Lipshultz LI. Estimating the number of vasectomies performed annually in the United States: data from the National Survey of Family Growth. J Urol. 2010; 184: 2068-72. PMid:20850832. https://doi.org/10.1016/j.juro.2010.06.117

[3] Engelmann UH, Schramek P, Tomamichel G, et al. Vasectomy reversal in central Europe: results of questionnaire of urologists in Austria, Germany and Switzerland. J Urol. 1990; 143: 64-67. https://doi.org/10.1016/S0022-5347 (17) 39867-1

[4] Sandlow JI, Nagler H M. Vasectomy and vasectomy reversal: important issues. Preface. Urol Clin North Am. 2009; 36: xiii-xiv. PMid:19643230. https://doi.org/10.1016/j.ucl.2009.06. 001

[5] Schwarzer JU, Steinfatt $\mathrm{H}$. Current status of vasectomy reversal. Nat Rev Urol. 2013; 10: 195-205. PMid:23399733. https://doi.or g/10.1038/nrurol.2013.14

[6] Dohle GR, Diemer T, Kopa Z, et al; European Association of Urology Working Group on Male Infertility. European Association of Urology guidelines on vasectomy. Eur Urol. 2012; 61: 159-63.
PMid:22033172. https://doi.org/10.1016/j . eururo. 2011. 10.001

[7] Sharlip ID, Belker AM, Honig S, et al. American Urological Association. Vasectomy: AUA guideline. J Urol. 2012; 188(6 Suppl): 2482-91. PMid:23098786. https://doi .org/10.1016/j . juro .2012 .09 .080

[8] Zhao K, Wu L, Kong X, et al. Long-term safety, health and mental status in men with vasectomy. Sci Rep. 2018; 8: 15703. PMid:30356207. https://doi.org/10.1038/s41598-018-33989-5

[9] Jee SH, Hong YK. One-layer vasovasostomy: microsurgical versus loupe-assisted. Fertil Steril. 2010; 94: 2308-11. PMid:20074726. https://doi.org/10.1016/j.fertnstert.2009.12.013

[10] Lipshultz LI, Rumohr JA, Bennett RC. Techniques for vasectomy reversal. Urol Clin North Am. 2009; 36: 375-82. PMid:19643239. https://doi.org/10.1016/j.ucl.2009.05.011

[11] Elzanaty S, Malm J, Giwercman A. Duration of sexual abstinence: epididymal and accessory sex gland secretions and their relationship to sperm motility. Hum Reprod. 2005; 20: 221-25. PMid:15550495. https://doi.org/10.1093/humrep/deh586

[12] Fox M. Vasectomy reversal-microsurgery for best results. Br J Urol. 1994; 73: 449-53. PMid:8199836 https://doi.org/10.1111/j. 1464-410X . 1994.tb07613.x 